\title{
A fuzzy MADM approach for project selection: a six sigma case study
}

\author{
Rajeev Rathi ${ }^{a^{*}}$, Dinesh Khanduja ${ }^{\mathrm{b}}$ and S.K.Sharma ${ }^{\mathrm{c}}$
}

${ }^{a}$ Research Scholar, Department of Mechanical Engineering, National Institute of Technology, Kurukshetra, Haryana, India, 136119

${ }^{b}$ Professor, Department of Mechanical Engineering, National Institute of Technology, Kurukshetra, Haryana, India, 136119

${ }^{c}$ Former Professor, Department of Mechanical Engineering, National Institute of Technology, Kurukshetra, Haryana, India, 136119

\section{H R O N I C L E}

Article history:

Received June 25, 2015

Received in revised format:

October 12, 2015

Accepted November 25, 2015

Available online

November 262015

Keywords:

Six Sigma

Fuzzy logic

Project selection

MADM

Modified digital logic

TOPSIS

VIKOR

\section{Introduction}

In this competitive era customers wants superior quality products and services, so organizations look for ways to improve their functional performance to deal with customer expectations. In the chase of improved performance and customer utmost satisfaction, Six Sigma has been acknowledged as a wellorganized methodology that efforts to improve organizational performance through spotting on customer requirements (Linderman et al., 2003). It is a commanding improvement tool that can be used to drive and continuously maintain transformational raise in the business. It is an organized approach to improve processes and services, since it is based on scientific and statistical tools to create significant reduction in variations (Johannsen et al., 2011). It has been accepted as a governing strategy that employs an incessant improvement methodology to reduce process variability and forced out capacity waste inside the processes using quality and statistical techniques (Rathi et al., 2015). Six Sigma

* Corresponding author. Tel: +91-1744-233455, mob: +91-9996886672, Fax: +91-1744-233455

E-mail address: rajeevrathi_1443@nitkkr.ac.in rathi.415@gmail.com (R. Rathi)

(C) 2016 Growing Science Ltd. All rights reserved.

doi: $10.5267 /$ j.dsl.2015.11.002 
improves organisational performance in order to boost customer's satisfaction on products and services. Many big corporations like Motorola, General Electric, Du Pont, Allied Signal, Honeywell, Sony etc. have implemented Six Sigma and saved millions of dollars (Treichler et al., 2002). As per many researchers; it is a statistically based improvement methodology that helps to improve company's processes by eliminating waste, costs and by improving effectiveness of the processes (Snee, 2004). It can be considered as a business strategy with an aim to reduce production costs and make considerable improvements in processes and savings through combined attempts of statistical and management approaches in an integrated manner (Hensley \& Dobie, 2005). It is a breakthrough strategy used for process improvement by using a set of prearranged tools and statistical techniques to evaluate process performances (Tang et al., 2007). It makes a deep analysis and an efficient decision making which aims for the optimal solution rather than a merely good one. The strategy is popular among manufacturing organisations not only for its stout tool set but also for its well organised application of DMAIC methodology (Gijo \& Scaria, 2014). It includes all essential elements for certifying a quality manufacturing, starting from the design to control, using quality tools into a system.

Six Sigma was evolved by Motorola Corporation on the manufacturing floor in 1980s. Six Sigma aim at Motorola was not just to manufacture defect free products, but to remove defects throughout the corporation. They defined Six Sigma as a quality enhancement methodology with an objective of dropping the number of defects to 3.4 parts per million opportunities. It was a move to refashion the capability and use of quality make-up in industrial amphitheatre (Chakrabarty \& Chuan Tan, 2007). It is a statistically supported process improvement business strategy that targets to lessen defects by identifying and eliminating causes of variation in processes. Six Sigma methodology make available the tools and techniques to build up the potential and decrease the defects in any business practice (Goh, 2002). The name Six Sigma has evolved from the Greek alphabet sigma (б). The Greek alphabet is used to symbolize standard deviation in statistics and to evaluate the variability. The performance of any business is deliberated by their resultant sigma level. In statistics it is defined as six standard deviations from mean value and in a parametric way shall include $99.99 \%$ of the yield (Goh, 2002). Six Sigma was just a quality improvement practice and works on continuous improvement approach, when it was initiated in mid 1980s. But without the directional support this approach was not so popular at that time. In late 1990s in next generation of Six Sigma; a new phase was adjoined by General Electric to Six Sigma approach named as "Define" in order to recognize and prioritize problems in a right directional way. The addition of this phase completes the DMAIC methodology now extensively used to successfully carry out Six Sigma projects. Define phase is the key step in selecting the best possible project by focusing on the customer necessities (Antony, 2006).

As Six Sigma is a project driven approach, it is necessary to prioritize projects which give greatest benefits to the organization. Prioritizing and selecting the Six Sigma improvement projects are most complicated tasks in real life situations (Snee \& Hoerl, 2003). Six Sigma projects may be dissimilar in goals, vagueness, intricacy, length and in several other aspects. Every project includes various amounts of misgivings and there is no risk free project (Fundin \& Cronemyr, 2003; Su \& Chou, 2008). Project selection is a key element for successful implementation of Six Sigma. Business entities should select Six Sigma projects in such a manner that they are directly attached to the targets and plans, since various productive areas of enhancement struggle for limited resources. Six Sigma project selection is one of the most commonly argued issue in the literature these days because most of the Six Sigma projects get failed due to improper selection of improvement projects (Banuelas et al., 2006). Project selection is the process of estimating individual projects, and then choosing most essential project to implement Six Sigma, so that the targets of the company will be accomplished. Right Six Sigma project selection is itself a task, if it is correctly conceded that the probable profits of Six Sigma can improve significantly (Banuelas Coronado \& Antony, 2002). Project selection has been referred to as a very crucial act in any Six Sigma project and literature review shows that it has been frequently taken up very carelessly. Many of the corporations did not have any project selection technique that helps in well-timed concluding of the projects. Appropriate project selection increases the success rate and acceptance of 
Six Sigma in any business. An appropriate project selection is a very important task for accomplishment of Six Sigma strategy due to the fact that wrong project selection can gravely affect the total efficiency and productivity of any industry. For flourishing of Six Sigma execution, the importance of appropriate project selection cannot be mistreated. Successful Six Sigma project execution can provide valuable outputs by utilizing various resources. Whenever various Six Sigma projects are contradictory for implementation, organization is paying attention in recognizing those projects that outcome in the utmost profit to the organization.

Present study mainly emphasize on Selection of the right Six Sigma project in an automotive manufacturing unit in India, which is always the most crucial tasks in the successful execution of Six Sigma in any business. When there are no clear edges in outlooks of decision makers (Six Sigma expert, production manager, technical and financial experts etc.) while selecting Six Sigma project. It becomes necessary to compute the best possible solution in terms of selecting appropriate project using a decision making approach. In many decision making methods existing in the literature, only quantitative criteria have been considered for Six Sigma project selection (De Boer et al., 2001). Various dominant factors are frequently not considered during decision making, like; partial information, qualitative decisive factor and vagueness likings (Zhang et al., 2009). Therefore, in this paper fuzzy MADM is used to recognize the proper Six Sigma project that outcomes in the utmost profit to the corporation. Fuzzy MADM is a combined application of fuzzy set theory and multi attribute decision making (MADM) approach to accomplish most efficient profit and effectiveness (Shemshadi et al., 2011; Vats \& Vaish, 2013). MADM has capability to selects the best alternative from to the existing resources (Agalgaonkar et al., 2005). MADM approach has been effectively used in a lot of decision making tasks in industrial and research field (Gwo-Hshiung, 2010). It includes a variety of decision making techniques like; Analytic Hierarchy Process (AHP) (Rathi et al., 2015), VlseKriterijumska Optimisacija I Kompromisno Resenje (VIKOR) (Tong, Chen, \& Wang, 2007), Technique for Order Preference by Similarity to Ideal Solution (TOPSIS) (Yong, 2006), Additive Weighting (AW) (Modarres \& Sadi-Nezhad, 2005), Weighted Product Method (WPM) (M. Wang, Liu, Wang, \& Lai, 2010) and many more, and among these, VIKOR and TOPSIS are the outstanding approaches for decision making in complex situations (Opricovic \& Tzeng, 2004). There are various applications for the VIKOR and TOPSIS approaches as reported in literature in various sectors like; material selection (Anojkumar et al., 2015), supply chain, supplier selection (Wu \& Liu, 2011), health care sector (Zeng et al., 2013), renewable energy project selection (San Cristóbal, 2011), machine tool selection (Önüt et al., 2008) and many more(Devi, 2011; Önüt \& Soner, 2008). Current study deals with the selection of right Six Sigma project for improvement to reduce down time in Escorts Auto Products division of Escorts Group India. It involves the selection of improvement project from six alternatives at selected site. The purpose of this paper is to exploit the capability of VIKOR and TOPSIS approach to select right Six Sigma project that will improves overall operational performance under fuzzy environment using modified digital logic (MDL) weights.

\section{Evaluation Criteria for Six Sigma Project Selection}

The project selection problem with having a common factors and conflicting criteria can be well resolve by MADM methods, since these methods are used for solving paradoxical plans with different selection parameters (qualitative and quantative both). For a proper and most favourable selection of Six Sigma project, the decision maker should need proper selection criteria to be considered. For this seven critical parameters were recognized at selected site in India. The recognized parameters are taken out from the views of decision makers and excavated from literature based upon the requirements and prospects of the industry where the final Six Sigma project will be executed (Ayağ \& Özdemir, 2011; Nguyen et al., 2014). Alternatives should be assessed according to considered criteria, and the decision maker's preference must be expressed by weights to agreed criteria. 


\begin{tabular}{|c|c|c|c|}
\hline S.no & Parameters & Code & description \\
\hline 1 & $\begin{array}{l}\text { Down Time } \\
\text { Cost }\end{array}$ & $\mathrm{C}_{1}$ & $\begin{array}{l}\text { It is a main factor for investigating critical reasons of breakdown. It } \\
\text { includes the cost of breakdown, maintenance, repair and all activities } \\
\text { necessary to meet all its functional requirements throughout the service } \\
\text { life. It becomes critical to estimate such costs. }\end{array}$ \\
\hline 2 & Repair Time & $\mathrm{C}_{2}$ & $\begin{array}{l}\text { It is the Portion of breakdown time during which one or more experts } \\
\text { are working on a system to affect a repair. Repair time includes } \\
\text { preparation time, fault detection time, fault correction time and final bind } \\
\text { up time. }\end{array}$ \\
\hline 3 & Reliability & $\mathrm{C}_{3}$ & $\begin{array}{l}\text { It is the prime factor for selecting critical reasons of breakdown in } \\
\text { manufacturing units. It defines of how reliable a system is. It shows the } \\
\text { failure rate of each parameter responsible for breakdown in automotive } \\
\text { manufacturing. Reliability is an attribute of any that consistently } \\
\text { performs according to its specifications. }\end{array}$ \\
\hline 4 & Rejection & $\mathrm{C}_{4}$ & $\begin{array}{l}\text { It is also a key factor for investigating critical reasons of capacity } \\
\text { wastage. It includes the wastage of capacity due to rejection (in-process } \\
\text { or final) during production. }\end{array}$ \\
\hline 5 & Productivity & $\mathrm{C}_{5}$ & $\begin{array}{l}\text { Productivity is a prime measure of the efficiency of any production } \\
\text { system. Productivity is a crucial factor in measuring and estimating } \\
\text { production performance of firms. }\end{array}$ \\
\hline 6 & $\begin{array}{l}\text { Working } \\
\text { Environment }\end{array}$ & $\mathrm{C}_{6}$ & $\begin{array}{l}\text { Working environment go beyond just energy efficiency and attempt to } \\
\text { rate an effort with regard to the total environmental stewardship of a unit. } \\
\text { It includes minimum wastage, low energy consumption and user friendly } \\
\text { environment. In this regard working environment is significantly more } \\
\text { encompassing than just energy. A healthy working environment on shop } \\
\text { floor improves its productivity. }\end{array}$ \\
\hline 7 & Safety & $\mathrm{C}_{7}$ & $\begin{array}{l}\text { There are common hazards associated with the use of shop floor } \\
\text { equipment and tools. Working safely is the first thing because the safe } \\
\text { way is the correct way. The costs of accidents and ill health to } \\
\text { engineering shop floors may be disproportionately high. Many } \\
\text { employees are 'key' workers whose losses through injury or ill health } \\
\text { severely disrupt production and lowers productivity and profitability. }\end{array}$ \\
\hline
\end{tabular}

\section{Methods}

\subsection{Modified Digital Logic}

All the selected parameters have their different effect for selection of an appropriate Six Sigma project which is considered as the optimum for the application, therefore cannot be allocated equal weighting. So it turns out to be essential to find out the priority of each parameter as per the firm's resources. MDL is well recognized method to compute the weights of selection criteria in such circumstances. It is the amended version of Digital logic method. It has various incredible advantages over digital logic (Dehghan-Manshadi et al., 2007). It includes expert views to allocate primary priorities value as 1, 2 and 3 for less, equivalent and more significant parameters, respectively. Further, MDL decision table was created with pair wise comparison based on the views of decision makers. Before constructing the MDL table, it is necessary to work out the number of likely positive decisions using equation $\mathrm{N}=\mathrm{n}$ $(\mathrm{n}-1) / 2$, where $\mathrm{n}$ is the number of parameters. Further summation of all positive decisions (P) for a parameter on normalization directs to final weight $(\mathrm{Wj})$ as:

$$
W_{j}=\frac{P_{j}}{\sum_{j=1}^{n} P_{j}}
$$




\subsection{Fuzzy Logic}

Fuzzy Logic is mainly a multivalue logic that allows intermediary values to be defined between conventional assessments like true/false, good/bad, yes/no etc. Such values can be devised mathematically and processed by computers. This made an attempt to apply a more human thinking in the programming of computers. The importance of fuzzy logic estimates from the fact that the majority of approaches of human being- reasoning are approximate in nature. Fuzzy approach was introduced to deal with the problems where there are no clear limits between the two parameters (Zadeh, 1965). Fuzzy approach was used for multiple attribute decision making where the emphasis is on possibility rather than probability (Ribeiro, 1996). Fuzzy logic is based on a set theory. It comprises of a membership function within the interval $[0,1]$ which express the level of significance of an element for being the member of the set (Bevilacqua, Ciarapica, \& Giacchetta, 2006). A feature of fuzzy logic which is of particular importance in expert systems is that it provides a systematic structure for dealing with fuzzy values, e.g., most, many, few, not very many, etc. In this way, fuzzy logic includes both established logic and probability theory, and makes it likely to deal with dissimilar vagueness within single conceptual framework i.e. linguistic variables. These variables are used for all comparisons, which has been assigned numerical values without any enigma. A linguistic variable is a variable whose value are words or sentences in a natural or artificial language (Zadeh, 1975). The main application of the linguistic approach lie in the realm of humanistic system especially in the fields of artificial intelligence, human decision processes, pattern recognition, linguistics, psychology, economics and related areas (Bellman \& Zadeh, 1970). There are different fuzzy numbers depending on their situation. Some of which are triangular fuzzy numbers, trapezoidal fuzzy numbers, intersection of two triangular fuzzy numbers etc (Mahdavi-Amiri \& Nasseri, 2007). In present study trapezoidal fuzzy numbers were used ( $b_{1}, b_{2}, b_{3}, b_{4}$ ) for $\left\{b_{1}, b_{2}, b_{3}, b_{4} \in \mathrm{R} ; b_{1} \leq b_{2} \leq b_{3} \leq b_{4}\right\}$ as shown in fig 1 . It is often convenient to

work with trapezoidal fuzzy numbers because of its simplicity and information processing. The membership function $\mu_{b}(\mathrm{x})$ of trapezoidal fuzzy number is defined as;

$$
\mu_{b}(\mathrm{x})= \begin{cases}\frac{x-b_{1}}{b_{2}-b_{1}}, & x \in\left[b_{1}, b_{2}\right] \\ 1, & x \in\left[b_{2}, b_{3}\right] \\ \frac{b_{4}-x}{b_{4}-b_{3}}, & x \in\left[b_{3}, b_{4}\right] \\ 0, & \text { otherwise }\end{cases}
$$

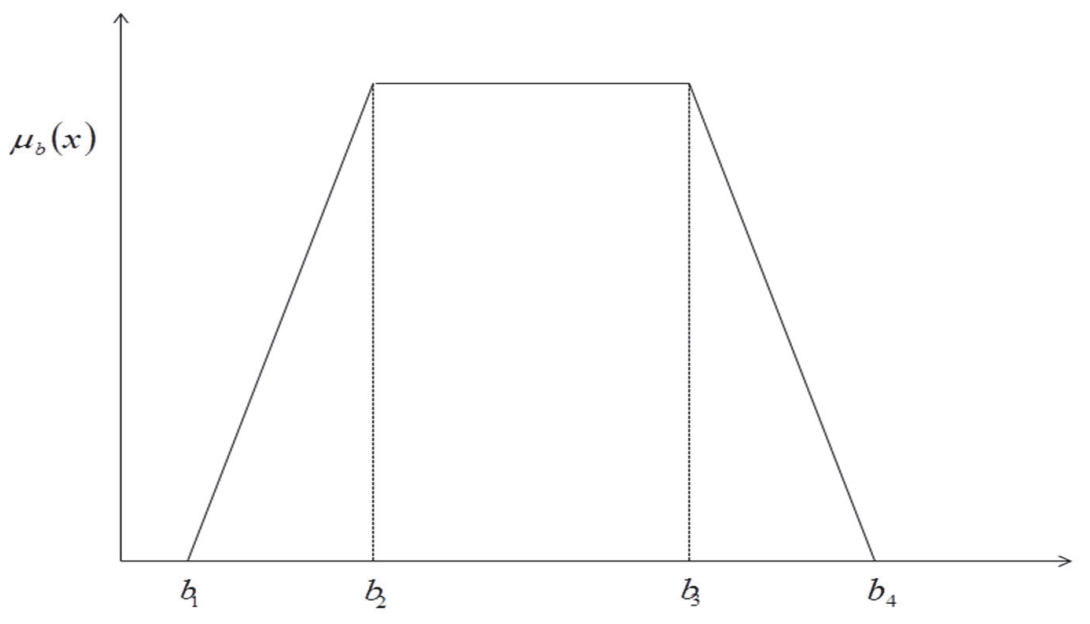

Fig. 1. Trapezoidal fuzzy number 


\subsection{TOPSIS}

Technique for order preference by similarity to an ideal solution (TOPSIS) method was presented by Hwang and Yoon in 1981 (Yoon \& Hwang, 1995). TOPSIS uses different weighting schemes and distance metrics to compares results of different sets of weights applied to set of multiple criteria data (Olson, 2004; Önüt \& Soner, 2008). The basic principle is that the chosen alternative should have the shortest pathway from the ideal solution and the excessive distance from the negative ideal solution. The ideal solution is a solution that takes advantage of the benefit criteria and lessens the cost criteria, whereas the negative ideal solution expands the cost criteria and minimizes the benefit criteria. Benefit criteria is for maximization, while the cost criteria is for minimization. The best alternative solution is one, which is closest to the ideal solution and farthest away from the negative ideal solution (Wang \& Elhag, 2006).

\subsection{VIKOR}

VlseKriterijumska Optimisacija I Kompromisno Resenje (VIKOR) method was developed for multi attribute decision making of intricate systems, mainly in circumstances where the decision makers are not capable to set preferences (Opricovic \& Tzeng, 2004). VIKOR prioritize alternatives and determines the compromise solution (feasible solution), which is the nearest to the ideal, and a compromise solution means a concord set up by mutual compromises (Chen \& Hwang, 1992). For any problem, a feasible solution with contradictory criteria can help the decision makers to make an ultimate decision. This method uses linear normalization to eliminate the units of criterion function. This method provides robust prioritization because it actively reflects the views of numerous collections and reflects vagueness in the input data.

\section{Application of proposed Methodology}

This section explains the steps involved in the subjective fuzzy VIKOR and fuzzy TOPSIS approach for right Six Sigma project selection in an automotive industry. The approach utilizes MDL weights for pair wise comparison among all considered criteria followed by fuzzy logic approach with VIKOR and TOPSIS methods to obtain best alternatives. It includes following steps:

Step 1: calculation of MDL weights.

As discussed in section 3.1, MDL weights $\left(W_{j}\right)$ are calculated for all project selection parameters. This gives the weights of different criteria.

Step 2: Describe linguistic variables, appropriate membership function and equivalent fuzzy numbers. A set of fuzzy rates is required in order to compare all the alternatives for each criterion. These fuzzy terms are assigned by the decision makers and responsible for intra criterion comparisons of the alternatives.

Step 3: Construction of decision matrix.

Let $p$ be the parameters and $q$ be the alternatives. For $k$ number of decision makers in the projected model for the aggregated fuzzy rating for $C_{j}$ criterion is represented as $\mathrm{x}_{\mathrm{ijk}}=\left\{\mathrm{x}_{\mathrm{ijk} 1}, x_{i j k 2}, x_{i j k} 3, x_{i j k 4\}}\right.$. For $i$ $=1,2, \ldots . p ; j=1,2 \ldots . q ; k=1,2 \ldots . . x_{i j k}$ is calculated as (Shemshadi et al., 2011),

$$
\left\{\begin{array}{l}
x_{i j 1}=\min _{k}\left\{b_{i j k 1}\right\} \\
x_{i j 2}=\frac{1}{k} \sum b_{i j k 2} \\
x_{i j 3}=\frac{1}{k} \sum b_{i j k 3} \\
x_{i j 4}=\max _{k}\left\{b_{i j k 4}\right\}
\end{array}\right.
$$


Thus the obtained decision matrix $(M)$ is shown as:

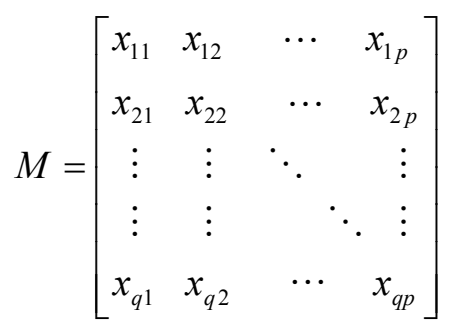

\section{Step 4: Normalization}

The first essential requirement of any comparison is that all quantities being contrasted should be on the same scale. Therefore, aggregated fuzzy rating was normalized in this step. Mathematically, normalization was carried out using the following Equations:

$$
\begin{aligned}
& \mu_{i j}=\left(\frac{x_{i j 1}}{x_{i j 1}^{+}}, \frac{x_{i j 2}}{x_{i j 2}^{+}}, \frac{x_{i j 3}}{x_{i j 3}^{+}}, \frac{x_{i j 4}}{x_{i j 4}^{+}}\right), \quad j \in J \\
& \mu_{i j}=\left(\frac{x_{i j 1}^{-}}{x_{i j 1}}, \frac{x_{i j 2}^{-}}{x_{i j 2}}, \frac{x_{i j 3}^{-}}{x_{i j 3}}, \frac{x_{i j 4}^{-}}{x_{i j 4}}\right), \quad j \in J^{\prime}
\end{aligned}
$$

where $x_{i j 4}^{+}=\max \left(x_{i j 4}\right), j \in J ; \quad x_{i j 1}^{-}=\min \left(x_{i j 1}\right), j \in J^{\prime}$ where $J$ corresponds to higher desired value and $J^{\prime}$ corresponds to lower desired value.

\section{Step 5: Defuzzification}

Defuzzification is a method of converting fuzzy output to crisp value (enumerated result) in fuzzy logic by real valued functions. It is performed to obtain the crisp values for each criterion corresponding to each alternative. The input for the procedure is the cumulative set and the output is a single number. This provides a quantitative value for the linguistic variables and fuzzy numbers assigned based on the verbal reasoning of the decision makers. Following equation lead to the crisp values:

$$
\begin{aligned}
& f_{\mathrm{ij}}=\operatorname{Defuzz}\left(x_{i j}\right)=\frac{\int \mu(x) \cdot x d x}{\int \mu(x) \cdot d x} \\
& =\frac{\int_{x_{i j 1}}^{x_{i j 2}}\left\{\left(x-x_{i j 1}\right) /\left(x_{i j 2}-x_{i j 1}\right)\right\} \cdot x d x+\int_{x i j 2}^{x_{i j 3}} x d x+\int_{x_{i j 3}}^{x_{i j 4}}\left\{\left(x_{i j 4}-x\right) /\left(x_{i j 4}-x_{i j 3}\right)\right\} \cdot x d x}{\int_{x_{i j 1}}^{x_{i j 2}}\left\{\left(x-x_{i j 1}\right) /\left(x_{i j 2}-x_{i j 1}\right)\right\} d x+\int_{x i j 2}^{x_{i j 3}} d x+\int_{x_{i j 3}}^{x_{i j 4}}\left\{\left(x_{i j 4}-x\right) /\left(x_{i j 4}-x_{i j 3}\right)\right\} \cdot x d x} \\
& =\frac{-x_{i j 1} x_{i j 2}+x_{i j 3} x_{i j 4}+(1 / 3)\left(x_{i j 4}-x_{i j 3}\right)^{2}+(1 / 3)\left(x_{i j 2}-x_{i j 1}\right)^{2}}{-x_{i j 1}-x_{i j 2}-x_{i j 3}+x_{i j 4}}
\end{aligned}
$$

The crisp values, thus obtained are integrated with MDL weights to calculate final ranking using VIKOR and TOPSIS approach as discussed below. 


\section{VIKOR Approach Steps}

Step 6: Determination of ideal and negative ideal solutions;

The ideal solution $f^{*}$ and negative ideal solution $f^{-}$are determined as

$$
\begin{aligned}
& f^{*}=\left\{\max f_{i j}\right\} \\
& f^{-}=\left\{\min f_{i j}\right\}
\end{aligned}
$$

Step 7: Calculation of utility and regret measures

$$
\begin{aligned}
& S_{i}=\sum_{j=1}^{n} W_{j} \frac{\left(f_{j}^{*}-f_{i j}\right)}{\left(f_{j}^{*}-f_{j}^{-}\right)} ; \quad \forall i \\
& R_{i}=\operatorname{Max}_{j}\left[W_{j} \frac{\left(f_{j}^{*}-f_{i j}\right)}{\left(f_{j}^{*}-f_{j}^{-}\right)}\right] ; \quad \forall i
\end{aligned}
$$

where $\mathrm{S}_{i}$ and $\mathrm{R}_{i}$ represent the utility and regret measures, respectively and $\mathrm{W}_{j}$ is the relative weight assigned to the Jth parameter using MDL.

Step 8: Calculation of VIKOR index

$$
Q_{i}=v\left[\frac{S_{i}-S^{*}}{S^{-}-S^{*}}\right]+(1-v)\left[\frac{R_{i}-R^{*}}{R^{-}-R^{*}}\right] ; \quad \forall i
$$

where $\mathrm{Q}_{i}$ represents ith alternatives VIKOR value, $\mathrm{v}$ is the group utility weight, it is generally considered as 0.5 (unsupervised) and;

$$
\begin{aligned}
& S^{*}=\min _{i}\left(S_{i}\right) ; \\
& S^{-}=\max _{i}\left(S_{i}\right) ; \\
& R^{*}=\min _{i}\left(R_{i}\right) ; \\
& R^{-}=\max _{i}\left(R_{i}\right) ;
\end{aligned}
$$

Six Sigma Project with least value of VIKOR index $\mathrm{Q}_{i}$ is preferred.

\section{TOPSIS Approach Steps}

Step 5: Normalized the matrix as given below:

$$
r_{i j}=\frac{f_{i j}}{\sqrt{\sum_{i=1}^{m}\left(f_{i j}\right)^{2}}} ; \forall_{j}
$$

Step 6: Calculate the weighted normalized decision matrix as given:

$$
V_{i j}=\left[r_{i j}\right]_{m \times n} \times\left[W_{j}\right]_{n \times m}^{\text {diagonal }}
$$


Step 7: Calculate the positive ideal and negative ideal solution:

The positive ideal solution $V_{j}^{+}$and negative ideal solution $V_{j}^{-}$are as given below:

$$
\begin{aligned}
& V_{j}^{+}=\left\{\left(\max V_{i j}, j \in J_{1}\right),\left(\min V_{i j}, j \in J_{2}\right), i=1,2,3 \ldots . . m\right\} ; \forall j \\
& V_{j}^{-}=\left\{\left(\min V_{i j}, j \in J_{1}\right),\left(\max V_{i j}, j \in J_{2}\right), i=1,2,3 \ldots . . m\right\}, \forall j
\end{aligned}
$$

where $J_{1}$ and $J_{2}$ represents higher best and lower best criteria respectively.

Step 8: Calculate the distance $d_{i}^{+}$and $d_{i}^{-}$from the positive ideal solution and negative ideal solution respectively

$$
\begin{aligned}
& d_{i}^{+}=\left[\sum_{j=1}^{n}\left(V_{i j}-V_{j}^{+}\right)^{2}\right]^{0.5}, i=1,2,3, \ldots . . m \\
& d_{i}^{-}=\left[\sum_{j=1}^{n}\left(V_{i j}-V_{j}^{-}\right)^{2}\right]^{0.5}, i=1,2,3, \ldots . . m
\end{aligned}
$$

Step 9: Calculation of TOPSIS rank index:

$$
C_{i}^{+}=\frac{d_{i}^{-}}{d_{i}^{-}+d_{i}^{+}}
$$

Six Sigma Project with highest rank index $C_{i}^{+}$are preferred.

\section{Results and Discussion}

Project selection decision in Six Sigma methodology is a very challenging assignment. The project selection in early phase of Six Sigma required high proficiency in decision making to select proper project from all given alternatives. In this study, in brainstorming sessions with decision makers like production manager, supervisors, machine operators and financial experts etc; it is concluded that selection of the optimal Six Sigma project from the accepted six important projects (alternatives) for improvement depends on seven selection criteria (parameters) as discussed in Section 2, which carried a significant impact on selection of alternatives. It has been closely observed that impact of these parameters differ from shop floor of industry to industry. As these parameters are identified, the next step is to prioritize these parameters, as to which of these have more impact on the identified alternatives. MDL approach was used to prioritize these parameters and in order to compare these distinct parameters, numeric priority values are assigned to the parameters on a scale of 1-3 and a set of pair wise matrix was made to carry out comparison.

\section{Table 1}

Subjective weights of the evaluation criteria calculated using MDL

\begin{tabular}{lcccccccccc}
\hline Parameters & $\mathrm{C}_{1}$ & $\mathrm{C}_{2}$ & $\mathrm{C}_{3}$ & $\mathrm{C}_{4}$ & $\mathrm{C}_{5}$ & $\mathrm{C}_{6}$ & $\mathrm{C}_{7}$ & Positive Decision & Weights & Rank \\
\hline Down Time Cost $\left(\mathrm{C}_{1}\right)$ & 2 & 3 & 1 & 3 & 2 & 3 & 3 & 15 & 0.179 & 2 \\
Repair Time $\left(\mathrm{C}_{2}\right)$ & 1 & 2 & 1 & 3 & 2 & 3 & 3 & 13 & 0.155 & 4 \\
Reliability $\left(\mathrm{C}_{3}\right)$ & 3 & 3 & 2 & 3 & 3 & 3 & 3 & 18 & 0.214 & 1 \\
Rejection $\left(\mathrm{C}_{4}\right)$ & 1 & 1 & 1 & 2 & 1 & 3 & 3 & 10 & 0.119 & 5 \\
Productivity $\left(\mathrm{C}_{5}\right)$ & 2 & 2 & 1 & 3 & 2 & 3 & 3 & 14 & 0.167 & 3 \\
Working Environment $\left(\mathrm{C}_{6}\right)$ & 1 & 1 & 1 & 1 & 1 & 2 & 1 & 6 & 0.071 & 7 \\
Safety $\left(\mathrm{C}_{7}\right)$ & 1 & 1 & 1 & 1 & 1 & 3 & 2 & 8 & 0.095 & 6 \\
\hline
\end{tabular}


Table 1 summarizes the relative decision matrix formed on the basis of pair-wise comparison and the weights are calculated for considered criteria. Reliability comes out as the leading Six Sigma project selection parameter; while working environment was found to be the least dominant parameter for selection.

Bar chart shows the contribution of all important parameters towards the selection of proper Six Sigma project as demonstrated in Fig. 2. The hierarchical structure for the selection of proper project is shown in Fig. 3. Level 1 specifies our target on selection of the proper Six Sigma project that has to be selected from the identified six important projects (alternatives) for improvement specifies in level 2. Level 3 specifies that the project selection alternatives are entirely interdependent on critical selection parameters; this shows the intricacy of the problem. Furthermore, this is a time consuming practice and considerable knowledge of both technological as well as economic aspects is needed in this case.

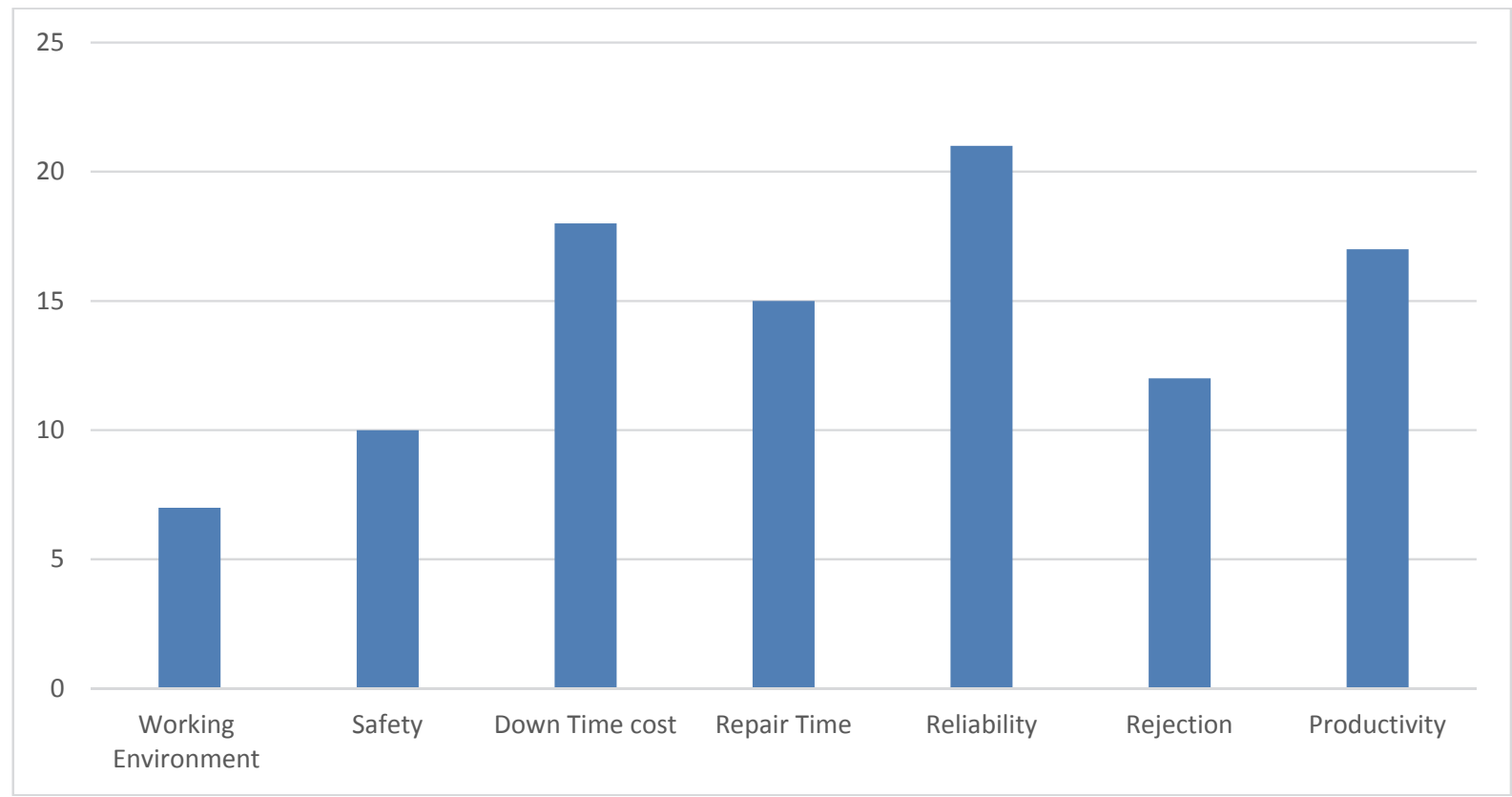

Fig. 2. Contribution of all important parameters towards the selection of proper Six Sigma project

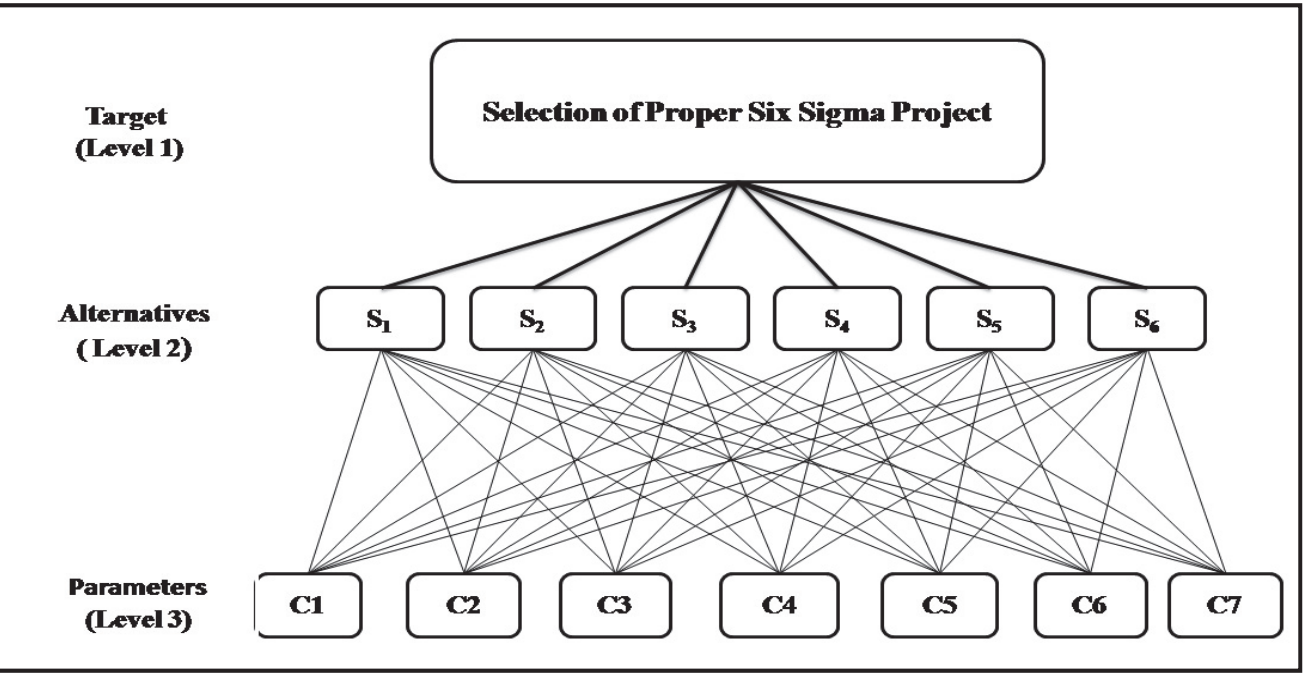

Fig. 3. Schematic hierarchical structure for the selection of proper Six Sigma project 
Further next, comparison of all alternatives with each parameter was carried out based on fuzzy logic approach. Linguistic variables were used for the selection of proper Six Sigma project, these variables further converted into corresponding fuzzy numbers. Table 2 presents the conversion of linguistic variables into fuzzy numbers for this problem. The highest range of linguistic variable is termed extremely high (EH) and the least is termed as extremely low (EL).

Table 2

Linguistic variables and corresponding fuzzy numbers

\begin{tabular}{ll}
\hline Linguistic Variable & Fuzzy number \\
\hline Extremely High (EH) & $(0.8,0.9,1.0,1.0)$ \\
Very high (VH) & $(0.7,0.8,0.8,0.9)$ \\
High (H) & $(0.5,0.6,0.7,0.8)$ \\
Above average (AA) & $(0.4,0.5,0.5,0.6)$ \\
Average (A) & $(0.2,0.3,0.4,0.5)$ \\
Very low (VL) & $(0.1,0.2,0.2,0.3)$ \\
Extremely low (EL) & $(0.0,0.0,0.1,0.2)$ \\
\hline
\end{tabular}

Table 3

Linguistic decision matrix of proper Six Sigma project selection for all evaluation criteria

\begin{tabular}{lccccccc}
\hline Production Shops & \multicolumn{7}{c}{ Evaluation Criteria (Parameters) } \\
\cline { 2 - 8 } (Alternatives) & $\mathrm{C}_{1}$ & $\mathrm{C}_{2}$ & $\mathrm{C}_{3}$ & $\mathrm{C}_{4}$ & $\mathrm{C}_{5}$ & $\mathrm{C}_{6}$ & $\mathrm{C}_{7}$ \\
\hline Metal Finishing Shop $\left(\mathrm{S}_{1}\right)$ & $\mathrm{H}$ & $\mathrm{H}$ & $\mathrm{VL}$ & $\mathrm{H}$ & $\mathrm{VL}$ & $\mathrm{A}$ & $\mathrm{A}$ \\
Shox. Machine Shop $\left(\mathrm{S}_{2}\right)$ & $\mathrm{EH}$ & $\mathrm{VH}$ & $\mathrm{VL}$ & $\mathrm{EH}$ & $\mathrm{VL}$ & $\mathrm{VL}$ & $\mathrm{EL}$ \\
Shox. Assembly Shop $\left(\mathrm{S}_{3}\right)$ & $\mathrm{H}$ & $\mathrm{H}$ & $\mathrm{A}$ & $\mathrm{AA}$ & $\mathrm{A}$ & $\mathrm{AA}$ & $\mathrm{H}$ \\
TFF Assembly Shop $\left(\mathrm{S}_{4}\right)$ & $\mathrm{A}$ & $\mathrm{A}$ & $\mathrm{AA}$ & $\mathrm{VL}$ & $\mathrm{H}$ & $\mathrm{H}$ & $\mathrm{H}$ \\
TFF Grinding Shop $\left(\mathrm{S}_{5}\right)$ & $\mathrm{VL}$ & $\mathrm{A}$ & $\mathrm{VH}$ & $\mathrm{AA}$ & $\mathrm{VH}$ & $\mathrm{VH}$ & $\mathrm{VH}$ \\
HCP Shop $\left(\mathrm{S}_{6}\right)$ & $\mathrm{H}$ & $\mathrm{A}$ & $\mathrm{VL}$ & $\mathrm{H}$ & $\mathrm{A}$ & $\mathrm{VL}$ & $\mathrm{A}$ \\
\hline
\end{tabular}

A Linguistic decision matrix of specified alternatives was constructed for all evaluation criteria during brainstorming session with decision makers as shown in table 3. For this problem a single decision matrix has been created rather than having a different decision matrix for each decision maker (as per discussion with decision makers). Further, Fuzzy values thus obtained are finally transformed into crisp values using equation 6. Crisp values thus obtained from aggregated fuzzy ratings are shown in table 4. Further next, estimated crisp values were analyzed with VIKOR approach, using equation 7 to 15 and crisp values were further analyzed with TOPSIS approach using equation 16 to 22 to find out the rank indices of all alternatives.

Table 4

Calculated crisp values for assigned fuzzy numbers

\begin{tabular}{cccccccc}
\hline $\begin{array}{c}\text { Production Shops } \\
\text { (Alternatives) }\end{array}$ & $\mathrm{C}_{1}$ & $\mathrm{C}_{2}$ & $\mathrm{C}_{3}$ & $\mathrm{C}_{4}$ & $\mathrm{C}_{5}$ & $\mathrm{C}_{6}$ & $\mathrm{C}_{7}$ \\
\hline $\mathrm{S}_{1}$ & 0.6667 & 0.6667 & 0.2333 & 0.6667 & 0.2333 & 0.3667 & 0.3667 \\
$\mathrm{~S}_{2}$ & 0.9444 & 0.8333 & 0.2333 & 0.9444 & 0.2333 & 0.2333 & 0.0778 \\
$\mathrm{~S}_{3}$ & 0.6667 & 0.6667 & 0.3667 & 0.5333 & 0.3667 & 0.5333 & 0.6667 \\
$\mathrm{~S}_{4}$ & 0.3667 & 0.3667 & 0.5333 & 0.2333 & 0.6667 & 0.6667 & 0.6667 \\
$\mathrm{~S}_{5}$ & 0.2333 & 0.3667 & 0.8333 & 0.5333 & 0.8333 & 0.8333 & 0.8333 \\
$\mathrm{~S}_{6}$ & 0.6667 & 0.3667 & 0.2333 & 0.6667 & 0.3667 & 0.2333 & 0.3667 \\
\hline
\end{tabular}




\section{Table 5}

Calculated VIKOR and TOPSIS ranking

\begin{tabular}{lcccc}
\hline Production Shops (Alternatives) & VIKOR Index & VIKOR Rank & TOPSIS Index & TOPSIS rank \\
\hline Metal Finishing Shop $\left(\mathrm{S}_{1}\right)$ & 0.1992 & 2 & 0.889 & 2 \\
Shox. Machine Shop $\left(\mathbf{S}_{2}\right)$ & $\mathbf{0 . 0 0 0 0}$ & $\mathbf{1}$ & $\mathbf{1 . 0 0 0}$ & $\mathbf{1}$ \\
Shox. Assembly Shop $\left(\mathrm{S}_{3}\right)$ & 0.2911 & 3 & 0.715 & 4 \\
TFF Assembly Shop $\left(\mathrm{S}_{4}\right)$ & 0.5871 & 5 & 0.139 & 5 \\
TFF Grinding Shop $\left(\mathrm{S}_{5}\right)$ & 0.7500 & 6 & 0.022 & 6 \\
HCP Shop $\left(\mathrm{S}_{6}\right)$ & 0.3619 & 4 & 0.778 & 3 \\
\hline
\end{tabular}

Table 5 displays subsequent rank indices and ranks for all Six Sigma projects (alternatives). The ranking of alternatives obtained by VIKOR and TOPSIS approach are approximately same. This shows the robustness of the obtained results. Current study shows that the compromise solution, closest to the ideal is obtained as Shox machine shop $\left(\mathrm{S}_{2}\right)$ as it's VIKOR and TOPSIS rank is highest among all selected alternatives. Therefore this shop has been selected as key priority project for further improvement using Six Sigma strategy. In current study production managers are given a decision making tool to determine the appropriate Six Sigma project at an early decision phase. Furthermore, the quality status of the selected industry has been extensively improved through execution of the Six Sigma project.

\section{Conclusions}

Six Sigma Projects of an automotive manufacturing unit are prioritized in present study. MADM methods are used for selection of proper Six Sigma project in Indian automotive industry. In this regard, six projects (alternatives) of the particular unit are ranked on the basis of selection criteria. Modified digital logic (MDL) method is used to calculate weights of all influencing parameters for evaluation of proper Six Sigma projects in an automotive industry. Reliability and working environment have been found to be most and least critical parameters, respectively. Further, the priority order of Six Sigma projects is determined using fuzzy VIKOR and fuzzy TOPSIS approach integration with MDL weights. Shox machine shop was found to be the most favourable Six Sigma Project for improvement at selected site. The results of the application reveal that the proposed approach can efficiently be used in practice for proper Six Sigma project selection problem. Present study validates the efficacy of fuzzy logic with VIKOR and TOPSIS approaches for proper Six Sigma project selection in Indian automotive industry.

\section{References}

Agalgaonkar, A., Kulkarni, S., \& Khaparde, S. (2005). Multi-attribute decision making approach for strategic planning of DGs. Paper presented at the Power Engineering Society General Meeting, 2005. IEEE.

Anojkumar, L., Ilangkumaran, M., \& Vignesh, M. (2015). A decision making methodology for material selection in sugar industry using hybrid MCDM techniques. International Journal of Materials and Product Technology, 51(2), 102-126.

Antony, J. (2006). Six sigma for service processes. Business Process Management Journal, 12(2), 234248.

Ayağ, Z., \& Özdemir, R. G. (2011). An intelligent approach to machine tool selection through fuzzy analytic network process. Journal of Intelligent Manufacturing, 22(2), 163-177.

Banuelas Coronado, R., \& Antony, J. (2002). Critical success factors for the successful implementation of six sigma projects in organisations. The TQM magazine, 14(2), 92-99.

Banuelas, R., Tennant, C., Tuersley, I., \& Tang, S. (2006). Selection of Six Sigma projects in the UK. The TQM Magazine, 18(5), 514-527. 
Bellman, R. E., \& Zadeh, L. A. (1970). Decision-making in a fuzzy environment. Management science, 17(4), B-141-B-164.

Bevilacqua, M., Ciarapica, F., \& Giacchetta, G. (2006). A fuzzy-QFD approach to supplier selection. Journal of Purchasing and Supply Management, 12(1), 14-27.

Chakrabarty, A., \& Chuan Tan, K. (2007). The current state of six sigma application in services. Managing Service Quality: An International Journal, 17(2), 194-208.

Chen, S.-J., \& Hwang, C.-L. (1992). Fuzzy multiple attribute decision making methods: Springer.

De Boer, L., Labro, E., \& Morlacchi, P. (2001). A review of methods supporting supplier selection. European Journal of Purchasing \& Supply Management, 7(2), 75-89.

Dehghan-Manshadi, B., Mahmudi, H., Abedian, A., \& Mahmudi, R. (2007). A novel method for materials selection in mechanical design: combination of non-linear normalization and a modified digital logic method. Materials \& design, 28(1), 8-15.

Devi, K. (2011). Extension of VIKOR method in intuitionistic fuzzy environment for robot selection. Expert Systems with Applications, 38(11), 14163-14168.

Fundin, A., \& Cronemyr, P. (2003). Use customer feedback to choose Six Sigma projects.

Gijo, E., \& Scaria, J. (2014). Process improvement through Six Sigma with Beta correction: a case study of manufacturing company. The International Journal of Advanced Manufacturing Technology, 71(1-4), 717-730.

Goh, T. N. (2002). A strategic assessment of Six Sigma. Quality and Reliability Engineering International, 18(5), 403-410.

Gwo-Hshiung, T. (2010). Multiple attribute decision making: methods and applications. Multiple Attribute Decision Making: Methods and Applications.

Hensley, R. L., \& Dobie, K. (2005). Assessing readiness for six sigma in a service setting. Managing Service Quality: An International Journal, 15(1), 82-101.

Johannsen, F., Leist, S., \& Zellner, G. (2011). Six sigma as a business process management method in services: analysis of the key application problems. Information Systems and E-Business Management, 9(3), 307-332.

Linderman, K., Schroeder, R. G., Zaheer, S., \& Choo, A. S. (2003). Six Sigma: a goal-theoretic perspective. Journal of Operations management, 21(2), 193-203.

Mahdavi-Amiri, N., \& Nasseri, S. (2007). Duality results and a dual simplex method for linear programming problems with trapezoidal fuzzy variables. Fuzzy sets and systems, 158(17), 19611978.

Modarres, M., \& Sadi-Nezhad, S. (2005). Fuzzy simple additive weighting method by preference ratio. Intelligent Automation \& Soft Computing, 11(4), 235-244.

Nguyen, H.-T., Dawal, S. Z. M., Nukman, Y., \& Aoyama, H. (2014). A hybrid approach for fuzzy multi-attribute decision making in machine tool selection with consideration of the interactions of attributes. Expert Systems with Applications, 41(6), 3078-3090.

Olson, D. L. (2004). Comparison of weights in TOPSIS models. Mathematical and Computer Modelling, 40(7-8), 721-727. doi: http://dx.doi.org/10.1016/j.mcm.2004.10.003

Önüt, S., Soner Kara, S., \& Efendigil, T. (2008). A hybrid fuzzy MCDM approach to machine tool selection. Journal of Intelligent Manufacturing, 19(4), 443-453.

Önüt, S., \& Soner, S. (2008). Transshipment site selection using the AHP and TOPSIS approaches under fuzzy environment. Waste Management, 28(9), 1552-1559.

Opricovic, S., \& Tzeng, G.-H. (2004). Compromise solution by MCDM methods: A comparative analysis of VIKOR and TOPSIS. European Journal of Operational Research, 156(2), 445-455.

Rathi, R., Khanduja, D., \& Sharma, S. (2015). Synergy of fuzzy AHP and Six Sigma for capacity waste management in Indian automotive industry. Decision Science Letters, 4(3), 441-452.

Ribeiro, R. A. (1996). Fuzzy multiple attribute decision making: a review and new preference elicitation techniques. Fuzzy sets and systems, 78(2), 155-181.

San Cristóbal, J. (2011). Multi-criteria decision-making in the selection of a renewable energy project in spain: The Vikor method. Renewable energy, 36(2), 498-502. 
Shemshadi, A., Shirazi, H., Toreihi, M., \& Tarokh, M. J. (2011). A fuzzy VIKOR method for supplier selection based on entropy measure for objective weighting. Expert Systems with Applications, $38(10), 12160-12167$.

Snee, R. D. (2004). Six-Sigma: the evolution of 100 years of business improvement methodology. International Journal of Six Sigma and Competitive Advantage, 1(1), 4-20.

Snee, R. D., \& Hoerl, R. W. (2003). Leading Six Sigma: a step-by-step guide based on experience with $G E$ and other Six Sigma companies: Ft Press.

Su, C.-T., \& Chou, C.-J. (2008). A systematic methodology for the creation of Six Sigma projects: A case study of semiconductor foundry. Expert Systems with Applications, 34(4), 2693-2703.

Tang, L. C., Goh, T. N., Lam, S. W., \& Zhang, C. W. (2007). Fortification of Six Sigma: expanding the DMAIC toolset. Quality and Reliability Engineering International, 23(1), 3-18.

Tong, L.-I., Chen, C.-C., \& Wang, C.-H. (2007). Optimization of multi-response processes using the VIKOR method. The International Journal of Advanced Manufacturing Technology, 31(11-12), 1049-1057.

Treichler, D., CARMICHAEL, B., Kusmanoff, A., Lewis, J., \& Berthiez, G. (2002). Design for Six Sigma: 15 lessons learned. Quality Progress, 35(1), 33-42.

Vats, G., \& Vaish, R. (2013). Piezoelectric material selection for transducers under fuzzy environment. Journal of Advanced Ceramics, 2(2), 141-148.

Wang, M., Liu, S., Wang, S., \& Lai, K. K. (2010). A weighted product method for bidding strategies in multi-attribute auctions. Journal of Systems Science and Complexity, 23(1), 194-208.

Wang, Y.-M., \& Elhag, T. M. S. (2006). Fuzzy TOPSIS method based on alpha level sets with an application to bridge risk assessment. Expert Systems with Applications, 31(2), 309-319. doi: http://dx.doi.org/10.1016/j.eswa.2005.09.040

Wu, M., \& Liu, Z. (2011). The supplier selection application based on two methods: VIKOR algorithm with entropy method and Fuzzy TOPSIS with vague sets method. International Journal of Management Science and Engineering Management, 6(2), 109-115.

Yong, D. (2006). Plant location selection based on fuzzy TOPSIS. The International Journal of Advanced Manufacturing Technology, 28(7-8), 839-844.

Yoon, K. P., \& Hwang, C.-L. (1995). Multiple attribute decision making: an introduction (Vol. 104): Sage Publications.

Zadeh, L. A. (1965). Fuzzy sets. Information and control, 8(3), 338-353.

Zadeh, L. A. (1975). The concept of a linguistic variable and its application to approximate reasoningI. Information sciences, 8(3), 199-249.

Zeng, Q.-L., Li, D.-D., \& Yang, Y.-B. (2013). VIKOR method with enhanced accuracy for multiple criteria decision making in healthcare management. Journal of medical systems, 37(2), 1-9.

Zhang, D., Zhang, J., Lai, K.-K., \& Lu, Y. (2009). An novel approach to supplier selection based on vague sets group decision. Expert Systems with Applications, 36(5), 9557-9563. 